\title{
PENGARUH KERJA KERAS TERHADAP HASIL BELAJAR SISWA IPA DI SMAN 1 KOTA JAMBI
}

\author{
Riska Fitriani ${ }^{1}$, Wita Ardina Putri ${ }^{2}$, Endah Febri Setya Rini ${ }^{3}$, Nanda Hasbullah Sehab ${ }^{4}$, \\ Maharani Rizky Pratiwi ${ }^{5}$ \\ Program Studi Pendidikan Fisika, Universitas Jambi ${ }^{1,2,3,4,5}$ \\ Email: riskafitriani04.rf@gmail.com
}

\begin{abstract}
Abstrak
Sulitnya meningkatkan karakter kerja keras belajar pada diri seseorang dapat berpengaruh terhadap hasil belajar yang diperoleh, dengan meningkatkan upaya kerja keras dalam belajar dapat memberikan dampak pada meningkatnya hasil belajar siswa. Tujuan dari penelitian ini yaitu untuk memperoleh gambaran spesifik mengenai pengaruh kerja keras terhadap hasil belajar fisika melalui materi dinamika rotasi dan kesetimbangan benda tegar di SMAN 1 Kota Jambi. Jenis penelitian yang digunakan berupa penelitian kuantitatif dengan jenis penelitian survei. Subjek dalam penelitian ini adalah 40 siswa IPA kelas XI di SMAN 1 kota jambi yang dilaksanakan pada bulan Oktober 2020. Instrumen yang digunakan peneliti yaitu berupa angket berisikan 25 item tentang kerja keras, dan 25 item untuk soal pilihan ganda. Data didapatkan dengan cara menyebarkan angket dan soal pilihan ganda kepada siswa IPA kelas XI di SMAN 1 kota Jambi, kemudian data yang terkumpul diolah sekaligus dianalisis dengan menggunakan program IBM SPSS Statistic 23.0. Hasil penelitian menunjukkan bahwa terdapat pengaruh signifikansi kerja keras belajar terhadap hasil belajar fisika siswa IPA kelas XI SMAN 1 kota Jambi dengan nilai signifikansi $0.000<0,05$, dengan kata lain semakin positif (semakin tinggi) kerja keras belajar seseorang terhadap pelajaran fisika maka hasil belajar yang didapatkan juga akan semakin baik.
\end{abstract}

Kata Kunci : kerja keras, hasil belajar, IPA

\begin{abstract}
The difficulty of increasing the character of learning hard work in a person can affect the learning outcomes, by increasing the effort to work hard in learning can have an impact on increasing student learning outcomes. The purpose of this study is to obtain a specific description of the effect of hard work on learning outcomes of physics through rotational dynamics and rigid object equilibrium at SMAN 1 Jambi City. The type of research used was quantitative research with survey research. The subjects in this study were 40 science students of class XI at SMAN 1 Kota Jambi held in October 2020. The instrument used by the researcher was a questionnaire containing 25 items about hard work, and 25 items for multiple choice questions. The data were obtained by distributing questionnaires and multiple choice questions to science students of class XI at SMAN 1 Jambi City, then the collected data were processed and analyzed using the IBM SPSS Statistics 23.0 program. The results showed that there was a significant effect of learning hard work on the learning outcomes of science students in class XI SMAN 1 Jambi City with a significance value of $0.000<0.05$, in other words, the more positive (the higher) a person's learning hard work towards physics lessons, the higher learning outcomes were obtained.
\end{abstract}

Key Words : hard work, learning outcomes, science

\section{PENDAHULUAN}

Pendidikan memiliki peran yang sangat penting [1] karena dengan pendidikan semua orang mampu mengubah perilaku dan pengetahuan menjadi lebih baik [2]. Ilmu pengetahuan khususnya IPTEK berkembang semakin pesat dan menuntut diimbangi dengan SDM yang berkualitas [3]. SMA merupakan salah satu jenjang pendidikan yang dapat menghasilkan SDM berkualitas dan memiliki daya saing tinggi [4]. Siswa yang memiliki SDM berkualitas 
dapat ditunjukkan dengan kemampuannya dalam memahami ilmu dan memahami karakter dirinya sendiri [5]. Pendidikan karakter merupakan proses menciptakan lingkungan sekolah yang mampu membantu siswa dalam pengembangan karakter yang baik dan bertanggung jawab [6]. Dalam tingkat pendidikan sekolah menengah atas, salah satu ilmu pengetahuan yang penting dipelajari adalah fisika [7].

Fisika adalah salah satu ilmu yang telah berkembang pesat, baik dari segi materi ataupun kegunaannya yang tidak terbatas pada cabang ilmu pengetahuan alam saja, tetapi juga bidang lain seperti teknologi, elektronika, arsitek, dan sebagainya, sehingga fisika merupakan ilmu yang menarik untuk dikuasai oleh semua siswa [8], namun mata pelajaran fisika termasuk sebagai mata pelajaran yang kurang disukai oleh siswa [9]. Sebagian siswa SMA Negeri se-Kota Jambi mengalami kesulitan untuk memahami materi fisika [10] karena setiap siswa harus memahami rumus-rumus dalam fisika dan mengaplikasikan dalam perhitungan [11], serta memuat hal-hal yang abstrak dan sulit dipahami [12][13]. Karena fisika diasumsikan sebagai pelajaran sulit, menyebabkan kurangnya keaktifan siswa, sehingga siswa malas belajar dan kurang merespon apa yang sedang mereka pelajari [14].

Pencapaian kompetensi melalui kegiatan pembelajaran di dalam kelas seringkali mengalami hambatan yang disebabkan oleh beberapa faktor, seperti lingkungan belajar [15], kesalahan siswa memahami konsep yang diberikan/diajarkan [16] dan juga karakter kerja keras belajar siswa. Kerja keras dapat dibentuk dengan latihan secara tekun untuk mencapai tujuan belajarnya [17]. Dalam proses belajar, sikap memiliki fungsi "dynamic forces" atau dapat didefinisikan sebagai kekuatan yang akan menggerakkan setiap individu untuk belajar [18]. Sikap diartikan sebagai tanda ekspresi atau respons siswa terhadap pembelajaran [19]. Sikap senang seorang siswa dalam pelajaran sains dapat terlihat dari bagaimana semangat siswa dalam belajar sains baik di luar mapun di dalam kelas [20]. Dalam pembelajaran fisika, tidak banyak siswa yang berani menjawab pertanyaan yang diberikan oleh guru [21] karena menurut siswa bukanlah hal yang mudah untuk memahami materi dan persoalan-persoalan yang terdapat dalam fisika [22]. Hal ini ditunjukkan dengan rerata hasil belajar yang diperoleh siswa masih sangat memprihatinkan [23]. Hasil belajar diartikan sebagai wujud nyata tercapainya tujuan pendidikan, dengan demikian hasil belajar yang diukur tergantung dari tujuan pendidikannya [24]. Oleh karena itu, bagi siswa yang memiliki sikap kerja yang tinggi dalam pembelajaran fisika akan mempengaruhi atau meningkatkan hasil belajar dari siswa tersebut.

Agar tercapai hasil belajar yang optimal perlu keterlibatan atau partisipasi yang tinggi dari siswa dalam pembelajaran [25] dimana siswa harus bekerja keras untuk menjawab persoalan fisika yang diberikan. Berhasil tidaknya pencapaian tujuan dari pendidikan banyak tergantung dari proses belajar dan bagaimana hasil yang diperoleh [26]. Salah satu materi fisika yang cukup menguras kerja keras siswa adalah materi dinamika rotasi dan kesetimbangan benda tegar dengan berbagai rumus-rumus yang harus dikuasai oleh siswa.

Berdasarkan uraian di atas, tujuan dari penelitian ini yaitu untuk memperoleh gambaran spesifik mengenai pengaruh kerja keras terhadap hasil belajar fisika melalui materi dinamika rotasi dan kesetimbangan benda tegar di SMAN 1 Kota Jambi. Sebelumnya telah dilakukan penelitian oleh [27] yang menunjukkan 
bahwa ada pengaruh antara sikap atau karakter rasa ingin tahu siswa terhadap pelajaran Fisika terkait baik atau tidaknya hasil belajar yang diperoleh siswa. Hal yang membedakan antara penelitiaan terdahulu dengan penelitian saat ini yaitu terdapat pada jenjang pendidikan yang diteliti, penelitian ini dilakukan pada jenjang SMA pada materi dinamika rotasi dan kesetimbangan benda tegar, sedangkan penelitian terdahulu dilakukan pada jenjang SMP materi fisika kelas VIII. Kebaruan dalam penelitian ini yaitu pada karakter yang diteliti dimana peneliti meneliti karakter kerja keras terhadap hasil belajar, sedangkan [27] meneliti karakter rasa ingin tahu terhadap hasil belajar. Temuan penelitian ini diharapkan kedepannya dapat berkontribusi untuk meningkatkan kerja keras belajar siswa terhadap pembelajaran fisika di SMAN 1 Kota Jambi.

Hipotesis Penelitian:

Terdapat pengaruh positif dan signifikan antara kerja keras siswa terhadap hasil belajar siswa kelas XI IPA pada pelajaran fisika di SMAN 1 Kota Jambi.

\section{METODE}

Penelitian yang digunakan peneliti adalah desain penelitian kuantitatif dengan jenis penelitian survei. Penelitian ini dilaksanakan di SMA Negeri 1 Kota Jambi tepatnya di Jl. Jenderal Urip Sumoharjo, Jambi, Provinsi Jambi. Subjek penelitian ini yaitu 40 siswa IPA kelas XI di SMAN 1 Kota Jambi yang dilaksanakan pada bulan Oktober 2020.

Teknik penelitian yang digunakan peneliti yaitu teknik purposive sampling. Penelitian dilakukan dengan mengumpulkan data menggunakan instrumen penilaian tes berupa kuesioner tentang kerja keras berjumlah 25 item yang terdiri atas 21 pernyataan positif dan 4 pernyataan negatif, dan soal pilihan ganda berjumlah 25 item materi dinamika rotasi dan kesetimbangan benda tegar. Kuesioner yang digunakan yaitu kuesioner tertutup dimana responden akan memilih dari serangkaian jawaban yang tersedia, sehingga cenderung cepat dijawab dan tidak memerlukan keterampilan menulis khusus dari setiap responden dimana dalam pengisian kuesioner responden dapat memilih jawaban sesuai dengan kepribadiannya.

Peneliti menggunakan teknik analisis data yaitu regresi yang dilengkapi dengan penjelasan naratif. Salah satu kegunaan regresi dalam suatu penelitian adalah untuk memprediksi atau meramalkan variabel terikat (Y) jika variabel bebas (X) sudah diketahui. Adapun variabel bebas dari penelitian yang dilakukan peneliti adalah kerja keras belajar siswa sementara variabel terikatnya hasil belajar siswa dalam menyelesaikan soal fisika. Data yang terkumpul nantinya diolah sekaligus dianalisis dengan menggunakan program IBM SPSS Statistic 23.0.

\section{HASIL DAN PEMBAHASAN}

Kerja keras diartikan sebagai tindakan perilaku yang patuh dan tertib dalam berbagai peraturan dan ketentuan yang ada [28], sedangkan hasil belajar diartikan sebagai penilaian akhir dari proses pembelajaran yang dilakukan berulangulang dan tersimpan dalam jangka waktu yang lama [29]. Dalam kegiatan pembelajaran diharapkan agar setiap siswa mendapatkan hasil belajar yang baik, tetapi pada kenyataannya tidak setiap siswa mampu mendapatkan hasil belajar yang memuaskan dan sesuai harapan.

Berdasarkan hasil analisis deskriptif yang dilakukan untuk mendapatkan gambaran mengenai karakteristik sampel penelitian dengan variabel penelitian, yaitu kerja keras belajar siswa $(X)$ dan juga hasil belajar fisika (Y). Pendeskripsian karakteristik tersebut dapat dilihat pada 
Tabel 1 yang diperoleh nilai rata-rata hitung (mean), median, modus, standar deviasi, nilai minimum dan nilai maximum. Berdasarkan hasil analisis data kerja keras belajar siswa pada Tabel 1 yang diperoleh melalui angket, distribusi ratarata hasil kerja keras belajar siswa dari sampel yang diambil sebanyak 40 orang siswa IPA kelas XI sebesar 75,0800 dengan median 75,2000, dan standar deviasi 6,67745. Hasil ini menunjukkan bahwa sebaran nilai kerja keras belajar siswa yang menjadi sampel berfluktuasi mulai dari yang rendah sampai yang tinggi. Nilai yang paling rendah adalah 61,60 dan nilai tertinggi 91,20 seperti disajikan pada Tabel 1 berikut ini

\begin{tabular}{|c|c|c|}
\hline \multicolumn{3}{|c|}{$\begin{array}{c}\text { Tabel 1. Statistik Deskriptif Variabel } \\
\text { Kerja Keras Belajar dan Hasil Belajar } \\
\text { Fisika }\end{array}$} \\
\hline Keterangan & $\mathbf{X}$ & $\mathbf{Y}$ \\
\hline $\mathrm{N}$ & 40 & 40 \\
\hline Mean & 75,0800 & 65,5000 \\
\hline Median & 75,2000 & 70,0000 \\
\hline Mode & 76,80 & 80,00 \\
\hline Std.Deviation & 6,67745 & 21,97784 \\
\hline Varian & 44,588 & 483,026 \\
\hline Minimum & 61,60 & 32,00 \\
\hline Maximum & 91,20 & 100,00 \\
\hline Sum & 3003,20 & 2620,00 \\
\hline
\end{tabular}

Adapun deskripsi hasil pengelompokan data kerja keras belajar siswa berdasarkan kategori: sangat rendah, rendah, sedang, tinggi, dan sangat tinggi terdapat pada Tabel 2 berikut ini.

\section{Tabel 2. Kategori Kerja Keras Belajar} Siswa

\begin{tabular}{ccccc}
\hline & Interval & f & $\%$ & Kategori \\
\hline \multirow{4}{*}{ Kerja } & $25,0-45,0$ & 0 & 0,0 & Sangat Rendah \\
Keras & $45,1-65,0$ & 0 & 0,0 & Rendah \\
& $65,1-85,0$ & 6 & 15,0 & Sedang \\
& $85,1-105,0$ & 30 & 75,0 & Tinggi \\
& $105,1-125,0$ & 4 & 10,0 & Sangat Tinggi \\
\hline
\end{tabular}

Dari Tabel 2 tampak bahwa jumlah siswa yang memiliki kerja keras dengan kategori sangat tinggi berjumlah 4 siswa dengan persentase $10,0 \%$. Siswa yang memiliki kerja keras dengan kategori tinggi berjumlah 30 siswa dengan persentase 75,0\%. Dan siswa yang memiliki kerja keras dengan kategori sedang berjumlah 6 siswa dengan persentase $15,0 \%$. Jadi, dapat disimpulkan bahwa kerja keras belajar fisika siswa SMAN 1 Kota Jambi tergolong dalam kategori Tinggi. Hal ini terjadi karena karakter kerja keras siswa selalu diterapkan di sekolah tersebut dengan adanya latihan-latihan soal yang diberikan oleh guru dan pemberian tugas mandiri kepada siswa sehingga karakter kerja keras siswa terhadap pelajaran fisika sudah cukup terbentuk dengan baik di SMA Negeri 1 Kota Jambi.

Tabel 3. Kategori Hasil Belajar Siswa

\begin{tabular}{ccccc}
\hline & Interval & $\mathrm{f}$ & $\%$ & Kategori \\
\hline \multirow{4}{*}{ Hasil } & $25,0-45,0$ & 0 & 0,0 & Gagal \\
Belajar & $45,1-65,0$ & 0 & 0,0 & Kurang Baik \\
& $65,1-85,0$ & 6 & 15,0 & Cukup Baik \\
& $35,1-105,0$ & 30 & 75,0 & Baik \\
& $05,1-125,0$ & 4 & 10,0 & Sangat Baik \\
\hline
\end{tabular}

Dari Tabel 3 tampak bahwa tidak ada siswa yang mendapatkan hasil belajar dalam kategori gagal dan kurang baik. Siswa yang memiliki nilai dengan kategori cukup baik berjumlah 6 siswa dengan persentase $15,0 \%$. Siswa yang memiliki nilai dengan kategori baik berjumlah 30 siswa dengan persentase 75,0. Dan siswa yang memiliki nilai dengan kategori sangat baik berjumlah 4 siswa dengan persentase $10,0 \%$. Jadi dapat disimpulkan bahwa hasil belajar fisika siswa SMAN 1 Kota Jambi tergolong dalam kategori Baik. Hal ini terjadi karena di sekolah tersebut selalu diadakan ulangan harian untuk setiap bab pembahasan yang telah selesai dipelajari dengan memberikan kesempatan kepada siswa untuk bertanya terkait materi yang belum dipelajari sebelum hari ujian/ulangan harian tiba, jika ada siswa yang memperoleh nilai di bawah kriteria ketuntasan minimal (KKM) yaitu kurang dari 75 maka guru akan memberikan remedial kepada siswa tersebut, sehingga 
siswa tersebut akan kembali mengulang mempelajari materi yang akan diremedialkan agar mendapatkan nilai di atas KKM, dengan demikian setiap siswa mendapatkan kesempatan untuk memperoleh hasil belajar yang memuaskan atau mencapai nilai kriteria ketuntasan minimal.

Pada penelitian ini akan diidentifikasi apakah kerja keras belajar siswa (X) mempunyai pengaruh terhadap hasil belajar fisika (Y) siswa IPA Kelas XI di SMAN 1 Kota Jambi menggunakan uji regresi linier sederhana dimana hipotesisnya berbunyi "Terdapat pengaruh positif dan signifikan antara kerja keras siswa terhadap hasil belajar siswa kelas XI IPA pada pelajaran fisika di SMAN 1 Kota Jambi”. Secara statistik, hipotesis tersebut ditulis sebagai berikut.

- $\mathrm{H} 0$ : $\beta \leq 0$ (kerja keras belajar siswa memiliki pengaruh positif dan tidak signifikan terhadap hasil belajar fisika siswa SMA Negeri 1 Kota Jambi).

- H1 : $\beta>0$ (Kerja Keras belajar siswa memiliki pengaruh positif dan signifikan terhadap hasil belajar fisika siswa SMA Negeri 1 Kota Jambi).

Tabel 4. Pengaruh Kerja Keras Belajar terhadap Hasil Belajar Fisika

\begin{tabular}{lrrrrr}
\hline \multirow{2}{*}{ Model } & \multicolumn{1}{c}{$\begin{array}{c}\text { Unstandardized } \\
\text { Coefficient }\end{array}$} & $\begin{array}{c}\text { Standardize } \\
d \\
\text { Coefficient }\end{array}$ & $T$ & Sig \\
\cline { 2 - 5 } & \multicolumn{7}{c}{ Std.Error } & Beta \\
\hline (Constant) & $-148,151$ & 11,908 & & $12,442,000$ \\
Kerja & 2,835 &, 155 &, 942 & $18,262,000$ \\
Keras & & & & \\
\hline
\end{tabular}

\begin{tabular}{|c|c|c|c|c|}
\hline 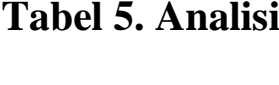 & $\begin{array}{l}\text { s Reg } \\
\text { terh }\end{array}$ & $\begin{array}{l}\text { esi antar } \\
\text { dap Has }\end{array}$ & $\begin{array}{l}\text { Pengart } \\
\text { Belajar }\end{array}$ & $\begin{array}{l}\text { Kerja Ken } \\
\text { sika }\end{array}$ \\
\hline Model & $R$ & $R$ Square & $\begin{array}{r}\text { Adjust } R \\
\text { Square } \\
\end{array}$ & $\begin{array}{l}\text { Std. Error of } \\
\text { the Estimate }\end{array}$ \\
\hline 1 &, $942^{\mathrm{a}}$ & 888, &, 885 & $\begin{array}{l}\text { Sangat Rendah } \\
\text { Rendah } \\
\text { Sedang } \\
\text { Tinggi } \\
\text { Sangat Tinggi }\end{array}$ \\
\hline
\end{tabular}

Dengan memperhatikan Tabel 4, maka diperoleh persamaan regresinya adalah $\mathrm{Y}=$ $-148,151+2,835 \mathrm{X}$. Dan dengan memperhatikan Tabel 5 koefisien Adjusted $R$ Square $R^{2}=0,885 \times 100 \%$ atau $88,5 \%$ yang menunjukkan bahwa hasil belajar fisika siswa SMAN 1 Kota Jambi dapat dijelaskan oleh kerja keras belajar siswa sebesar $88,5 \%$, dan sisanya sebesar $12,5 \%$ dijelaskan oleh faktor lain yang tidak diteliti dalalm penelitian ini. Besarnya persentase karakter kerja keras daripada faktor lain yang tidak diteliti di SMA Negeri 1 Kota Jambi terjadi karena di sekolah tersebut telah dilatih karakter kerja keras pada setiap siswanya dengan adanya pemberian latihan-latihan soal, tugas mandiri, tugas individu, tugas kelompok, ataupun ulangan harian dan ujian yang diberikan kepada siswa, sehingga siswa akan berusaha dan bekerja keras agar memperoleh hasil pembelajaran yang memuaskan, dan setiap siswa diperbolehkan untuk bertanya terkait materi yang membingungkan atau kurang dipahami agar dijelaskan kembali oleh guru yang bersangkutan. 
Berdasarkan Tabel 5 juga diketahui bahwa variabel kerja keras belajar siswa memiliki Sig. $=0,000$ lebih kecil dari $\alpha=0,05$ atau $t_{\text {thitung }}=18,262>t_{\text {tabel }}=2,024$. Hal ini menunjukkan ditolaknya hipotesis $\mathrm{H0}$ dan diterimanya hipotesis $\mathrm{Ha}$, artinya kerja keras belajar siswa memiliki pengaruh positif dan signifikan terhadap hasil belajar fisika siswa SMAN 1 Kota Jambi. Dengan kata lain, semakin positif (semakin tinggi) kerja keras belajar seseorang terhadap pelajaran fisika, maka hasil belajar yang didapatkan juga akan semakin baik. Hal ini terjadi dikarenakan di SMAN 1 Kota Jambi karakter kerja keras siswa sudah cukup terbentuk dengan baik dengan adanya latihan-latihan soal dan tugas mandiri yang diberikan oleh guru, terlebih lagi dengan adanya ulangan harian yang diberikan setelah bab pembahasan materi selesai dipelajari, sehingga siswa akan terus berusaha dan bekerja keras agar memahami setiap materi yang dipelajari dan mempersiapkan diri untuk menghadapi ulangan/ujian agar memperoleh hasil yang memuaskan dan mencapai kriteria ketuntasan minimal. Sikap atau karakter siswa memiliki pengaruh langsung positif terhadap hasil belajar IPA yang bermakna bahwa sikap atau karakter siswa yang positif akan mengakibatkan pada perolehan hasil belajar yang baik [18].

Hasil penelitian yang diperoleh peneliti juga relevan dengan hasil penelitian yang ditemukan oleh [27] dengan judul "Pengaruh Karakter Rasa Ingin Tahu Siswa terhadap Hasil Belajar Mata Pelajaran IPA Fisika di SMP Negeri 08 Muaro Jambi", bahwa sikap atau karakter setiap siswa sangat berpengaruh terhadap keberhasilan dan pencapaian hasil belajar dalam kegiatan pembelajaran materi Fisika.

\section{SIMPULAN}

Berdasarkan hasil analisis data yang telah diperoleh, dapat disimpulkan bahwa analisis deskriptif variabel kerja keras belajar siswa IPA kelas XI yang diberikan angket dominan memiliki kerja keras dengan kategori tinggi. Adapun analisis deskriptif variabel hasil belajar siswa IPA kelas XI yang diberikan soal pilihan ganda materi dinamika rotasi dan kesetimbangan benda tegar juga menunjukkan bahwa dominan siswa berada pada kategori tinggi. Berdasarkan hasil analisis data yang diperoleh tampak bahwa ada pengaruh positif yang signifikan antara kerja keras belajar terhadap hasil belajar fisika siswa IPA kelas XI di SMAN 1 Kota Jambi, hal ini menunjukkan bahwa kerja keras belajar fisika siswa memberikan kontribusi positif atau dukungan yang baik dalam usaha meningkatkan hasil belajar fisika siswa IPA kelas XI di SMA Negeri 1 Kota Jambi.

\section{DAFTAR PUSTAKA}

[1] R. Maulana, J. Jufrida, dan H. Pathoni. "Upaya Meningkatkan Pemahaman Konsep Siswa Menggunakan Discovery Based Learning dengan Bantuan LKS Digital Materi Fluida Dinamik Kelas XI SMAN 11 Kota Jambi”. Gravity J. Ilm. Penelit. dan Pembelajaran Fis., vol. 4, no. 2, pp. 67-81, 2018, doi: 10.30870/gravity.v4i2.4034.

[2] A. Astalini, D. A. Kurniawan, R. Melsayanti, dan A. Destianti. "Sikap terhadap Mata Pelajaran IPA di SMP se-Kabupaten Muaro Jambi". Lentera Pendidik. J. Ilmu Tarb. dan Kegur., vol. 21, no. 2, p. 214, 2018, doi: 10.24252/lp.2018v21n2i7.

[3] A. Zuhaida. "Program Sciences Kids Community Berbasis Group Investigation untuk Meningkatkan Kemampuan Pemecahan Masalah Siswa Madrasah Ibtidaiyah". $J$. Pendidik. Sains, vol. 6, no. 2, p. 13, 2018, doi: 10.26714/jps.6.2.2018.1320.

[4] A. Hidayatulah, Y. yushardi, dan S. 
Wahyuni. "Pengembangan Bahan Ajar Berbasis Web Interaktif dengan Aplikasi E-Learning Moodle pada Pokok Bahasan Besaran dan Satuan di SMA". J. Pembelajaran Fis. Univ. Jember, vol. 4, no. 2, p. 139047 , 2015.

[5] D. Aryani, A. Astalini, dan D. A. Kurniawan. "Identifikasi Sikap Siswa terhadap Mata Pelajaran IPA di SMP Se Kabupaten Muaro Jambi". J. Pijar Mipa, vol. 14, no. 2, pp. 111-127, 2019, doi: 10.29303/jpm.v14i2.1065.

[6] C. Mandriesa. "Identifikasi Religiusitas Siswa di SMA Adhyaksa 1 Jambi". J. Eval. Educ., vol. 1, no. 1, pp. 15-20, 2020.

[7] A. Joneska, Astalini, dan N. Susanti. "Perbandingan Hasil Belajar Fisika Menggunakan Strategi Pembelajaran Crossword Puzzle dan Index Card Match pada Materi Cahaya Kelas Viii SMP Negeri 3 Batanghari”. $J$. EduFisika, vol. 1, no. 1, pp. 28-31, 2016.

[8] A. Purwanto, M. Hendri, dan N. Susanti. "Studi Perbandingan Hasil Belajar Siswa Menggunakan Media PhET Simulations dengan Alat Peraga pada Pokok Bahsan Listrik Magnet di Kelas IX SMPN Kabupaten Tebo". J. EdulFisika, vol. 01, no. 01, pp. 22-27, 2016.

[9] Astalini, D. A. Kurniawan, R. Perdana, dan H. Pathoni. "Identifikasi Sikap Peserta Didik terhadap Mata Pelajaran Fisika di Sekolah Menengah Atas Negeri 5 Kota Jambi”. UPEJ Unnes Phys. Educ. J., vol. 8, no. 1, pp. 34-43, 2019 , doi: 10.15294/upej.v8i1.29510.

[10] H. Pathoni, F. B. Pujaningsih, M. Hendri, M. Maison, dan N. Nehru. "Pelatihan Pengembangan Content E-Learning untuk Guru IPA SEJALUKO". SELAPARANG J.
Pengabdi. Masy. Berkemajuan, vol. 3, no. 1, pp. 120-123, 2019, doi: 10.31764/jpmb.v3i1.1143.

[11] D. Oktaviana, Jufrida, dan Darmaji. "Penerapan RPP Berbasis Multiple Intelligences untuk Meningkatkan Aktivitas dan Hasil Belajar Fisika Siswa pada Materi Kalor dan Perpindahan Kalor X MIA 4 SMA Negeri 3 Kota Jambi”. J. EduFisika Vol., vol. 01, no. 01, pp. 7-12, 2016.

[12] D. A. P. Sari, M. Hidayat, dan W. Kurniawan. "Pengembangan Modul Elektronik Fisika Berbasis Pendekatan Saintifik Materi Getaran Harmonis Menggunakan Kvisoft Flipbook Maker". EduFisika J. Pendidik. Fis., vol. 4, no. 1, pp. 7991, 2019.

[13] A. Astalini dan D. A. Kurniawan. "Pengembangan Instrumen Sikap Siswa Sekolah Menengah Pertama terhadap Mata Pelajaran IPA". $J$. Pendidik. Sains, vol. 7, no. 1, p. 1, 2019, doi: 10.26714/jps.7.1.2019.17.

[14] M. Sipahutar, R. Dani, dan M. Hendri. "Model Discovery Learning Berbantuan Media Adobe Flash Cs 6 pada Materi Hukum Newton". EduFisika, vol. 3, no. 02, pp. 59-65, 2018 , doi: 10.22437/edufisika.v3i02.5259.

[15] Maison, Syahrial, Syamsurizal, and Tanti. "Learning Environment, Students' Beliefs, and SelfRegulation in Learning Physics: Structural Equation Modeling". $J$. Balt. Sci. Educ., vol. 18, no. 3, pp. 389-403, 2019, doi: 10.33225/jbse/19.18.389.

[16] M. Maison, N. Lestari, dan A. Widaningtyas. "Identifikasi Miskonsepsi Siswa pada Materi Usaha dan Energi". J. Penelit. Pendidik. IPA, vol. 6, no. 1, p. 32, 2019, doi: 10.29303/jppipa.v6i1.314.

[17] U. Wuryanti dan B. Kartowagiran. 
"Pengembangan Media Video Animasi Untuk Meningkatkan Motivasi Belajar dan Karakter Kerja Keras Siswa Sekolah Dasar". J. Pendidik. Karakter, vol. 6, no. 2, pp. 232-245, 2016, doi: 10.21831/jpk.v6i2.12055.

[18] A. Riwahyudin. "Pengaruh Sikap Siswa dan Minat Belajar Siswa terhadap Hasil Belajar IPA Siswa Kelas V Sekolah Dasar di Kabupaten Lamandau". J. Pendidik. Dasar, vol. 6, no. 1, p. 11, 2015, doi: 10.21009/jpd.061.02.

[19] A. Astalini, D. A. Kurniawan, N. Kurniawan, and L. Anggraini. "Evaluation of Student's Attitude Toward Science in Indonesia". Open J. Educ. Res., vol. 3, no. 2, pp. 3952, 2019, doi: 10.32591/coas.ojer.0302.01039h.

[20] D. A. Kurniawan, Astalini, dan L. Anggraini. "Evaluasi Sikap Siswa SMP terhadap IPA di Kabupaten Muaro Jambi”. J. Ilm. Didakt., vol. 19, no. 1, pp. 124-139, 2018.

[21] D. N. Khodijah, M. Hendri, dan Darmaji. "Upaya Meningkatkan Partisipasi dan Hasil Belajar dengan Menggunakan Model Pembelajaran Kooperatif Tipe Think Pair Share di Kelas XI MIA7 SMAN 1 Muaro Jambi”. J. EduFisika, vol. 01, no. Nomor 02, November, pp. 46-54, 2016.

[22] M. O. Setia, N. Susanti, dan W. Kurniawan. "Pengembangan Media Pembelajaran dengan Menggunakan Adobe Flash CS 6 pada Materi Hukum Newton Tentang Gerak dan Penerapannya". vol. 02, no. 02, pp. 42-57, 2017.

[23] D. S. Pasaribu. "Upaya Meningkatkan Minat dan Hasil Belajar Fisika Siswa dengan Menggunakan Model Pembelajaran Talking Stick pada Materi Listrik
Dinamis di Kelas X SMAN 10 Muaro Jambi". EduFisika, vol. 2, no. 01, pp. 61-69, 2017, doi: https://doi.org/10.22437/edufisika.v2 i01.4043.

[24] N. Kurnia, M. Hendri, dan H. Phatoni. "Hubungan Persepsi dengan Hasil Belajar Fisika Siswa Kelas X MIA di SMA Negeri 4 Kota Jambi dan SMA Negeri 11 Kota Jambi”. $J$. EduFisika, vol. 01, no. 02, pp. 5563, 2016.

[25] E. Dwijayanti dan H. Pathoni. "Penerapan Strategi Pembelajaran Aktif Tipe Peer Lessons untuk Meningkatkan Aktivitas dan Hasil Belajar Siswa pada Materi Suhu dan Kalor Kelas XA di SMAN 8 Kota Jambi”. J. EduFisika, vol. 01, no. 01, pp. 18-21, 2016.

[26] I. Marzuki dan L. Hakim. "Strategi Pembelajaran Karakter Kerja Keras". Rausyan Fikr J. Pemikir. dan Pencerahan, vol. 15, no. 1, pp. 7996, 2019, doi: 10.31000/rf.v15i1.1370.

[27] S. Novelyya. "Pengaruh Karakter Rasa Ingin Tahu Siswa terhadap Hasil Belajar Mata Pelajaran IPA Fisika di SMP Negeri 08 Muaro Jambi”. Briliant J. Ris. dan Konseptual, vol. 4, no. 2, pp. 174181, 2019, doi: 10.28926/briliant.v4i2.291.

[28] S. B. Sjukur. "Pengaruh Blended Learning terhadap Motivasi Belajar dan Hasil Belajar Siswa di Tingkat SMK". J. Pendidik. Vokasi, vol. 2, no. 3, pp. 368-378, 2013, doi: 10.21831/jpv.v2i3.1043.

[29] S. Nurhasanah dan A. Sobandi. "Motivasi Belajar sebagai Determinan Hasil Belajar Siswa". $J$. Pendidik. Manaj. Perkantoran, vol. 4, no. 1, p. 80, 2019, doi: 10.17509/jpm.v4i1.14958. 